\title{
Safety of prepectoral breast reconstruction after mastectomies: a single-arm meta-analysis
}

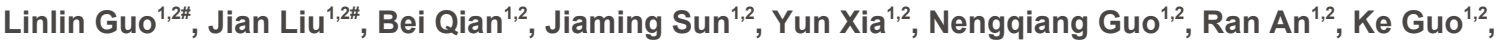 \\ Xiaoling Feng ${ }^{1,2}$ \\ 1Department of Plastic Surgery, Union Hospital, Tongji Medical College, Huazhong University of Science and Technology, Wuhan \\ 430022, Hubei, China. \\ ${ }^{2}$ Wuhan Clinical Research Center for Superficial Organ Reconstruction, Wuhan 430022, Hubei, China. \\ \#Authors contributed equally. \\ Correspondence to: Prof. Xiaoling Feng, Department of Plastic Surgery, Union Hospital, Tongji Medical College, Huazhong \\ University of Science and Technology, Wuhan 430022, Hubei, China. E-mail: fengxl2001@sina.com; Prof. Ke Guo, Department \\ of Plastic Surgery, Union Hospital, Tongji Medical College, Huazhong University of Science and Technology, Wuhan 430022, \\ Hubei, China. E-mail: gkiseric@126.com; Dr. Ran An, Department of Plastic Surgery, Union Hospital, Tongji Medical College, \\ Huazhong University of Science and Technology, Wuhan 430022, Hubei, China. E-mail: an_ran2018@163.com
}

How to cite this article: Guo L, Liu J, Qian B, Sun J, Xia Y, Guo N, An R, Guo K, Feng X. Safety of prepectoral breast reconstruction after mastectomies: a single-arm meta-analysis. Plast Aesthet Res 2021;8:34. https://dx.doi.org/10.20517/2347-9264.2021.18

Received: 5 Mar 2021 First Decision: 15 Apr 2021 Revised: 28 Apr 2021 Accepted: 21 May 2021 First online: 28 May 2021

Academic Editor: Raúl González-García Copy Editor: Xi-Jun Chen Production Editor: Xi-Jun Chen

\begin{abstract}
Aim: Currently, prepectoral breast reconstruction (PBR) is widely used in clinical practice, but its safety lacks highlevel epidemiological evidence. This meta-analysis intended to clarify the safety of PBR for clinicians.

Methods: The study followed the Preferred Reporting Items for Systematic reviews and Meta-Analyses guidelines. Two independent reviewers systematically searched six databases from 1 January 2000 to 27 March 2020 to identify eligible studies. Statistical analysis was performed using R GUI 3.6.3, and a random effects model was used to calculate the proportion with $95 \%$ confidence intervals (Cls). Subgroup analysis was conducted based on body mass index, proportion of patients receiving preoperative radiotherapy, surgical technique, and follow-up time.
\end{abstract}

Results: In total, 19 studies involving 1686 cases and 2551 breasts were included. The percentage of surgical success was $96.2 \%$, while the total complication rate was $15.4 \%$ (95\% Cl: $10.6 \%-20.9 \%$ ), hematoma rate was $4.3 \%$ (95\% Cl: $2.3 \%-6.9 \%$ ), infection rate was 3.4\% (95\% Cl: $2.0 \%-5.1 \%)$, and capsular contracture rate was $0.9 \%$ $(95 \% \mathrm{Cl}: 0.1 \%-2.6 \%)$. The results of the subgroup analysis show that: (1) the incidence of capsular contracture was higher in patients with lower weight, while other complications were minimal; (2) compared with the patients who

The Author(s) 2021. Open Access This article is licensed under a Creative Commons Attribution 4.0 International License (https://creativecommons.org/licenses/by/4.0/), which permits unrestricted use, sharing, adaptation, distribution and reproduction in any medium or format, for any purpose, even commercially, as long as you give appropriate credit to the original author(s) and the source, provide a link to the Creative Commons license, and indicate if changes were made. 
underwent two-stage expander-assisted PBR, those with direct to-implant PBR had lower incidences of surgical complications; (3) preoperative radiotherapy could be a risk factor for various postoperative complications; and (4) with the extension of follow-up time, the incidence of long-term complications increases.

Conclusion: This present work confirmed that PBR is a safe and reliable therapy with a higher success rate and a relatively lower rate of complications. Overall, PBR can be used as an alternative for sub-pectoral breast reconstruction.

Keywords: Prepectoral breast reconstruction, after mastectomies, single-arm meta-analysis

\section{INTRODUCTION}

Breast cancer is by far the most common malignancy in women ${ }^{[1]}$. Due to long-term physical, sexual, and psychological factors, breast reconstruction is considered to be an essential step after mastectomy ${ }^{[2]}$. The rate of women who undergo breast reconstruction following mastectomy continues to increase, and implantbased reconstruction remains as the most common reconstructive modality ${ }^{[3]}$. Compared with autologous tissue flaps, implant-based breast reconstruction has the advantages of simplicity and eliminating the need for surgery on the donor site ${ }^{[2]}$. Good candidates for implant-based mammoplasty are patients with body mass index $(\mathrm{BMI})<30 \mathrm{~kg} / \mathrm{m}^{2}$, mastectomy weight not exceeding $600 \mathrm{~g}$, no history of smoking and radiotherapy, nipple-sparing or skin-sparing mastectomy, and with a thickness of well-vascularized subcutaneous tissue $>1 \mathrm{~cm}$ to ensure sufficient skin coverage in front of the implant as well as good postoperative healing ${ }^{[4]}$. The traditional breast reconstruction surgery places an implant behind the pectoralis major muscle. However, several clinical studies indicated that it may cause animation deformity, pain, and muscle spasms and other complications ${ }^{[5]}$. With the advent of biosynthetic materials such as acellular dermal matrix (ADM) and titanium-coated polypropylene mesh, prepectoral breast reconstruction (PBR) after mastectomy has increased significantly over the past decades. ADM is then used to provide a complete covering tissue for the implant to eliminate direct contact between the implant and the flap ${ }^{[6]}$. Casella et al. ${ }^{[7]}$ reported the feasibility of PBR since it can retain a natural anatomical structure with a low rate of various complications, which is in accordance with another clinical study ${ }^{[8]}$. This operation can be carried out via two specific routes: direct to-implant (DTI) PBR, in which the implant is directly placed in front of the pectoralis major muscle, and two-stage expander-assisted (TSE) PBR, in which an expander is first placed in front of the pectoralis major muscle and then followed with an implant ${ }^{[4]}$. Complications such as hematoma, infection, necrosis, and capsular contracture may occur after breast reconstruction ${ }^{[9]}$. Capsular contracture is graded based on Spear-Baker classification, which classifies Grades III and IV as clinically significant with characteristic postoperative pain and often requiring reoperation ${ }^{[10]}$. Studies on safety of PBR surgery are relatively limited and heterogeneous. Thus, this meta-analysis was conducted to elucidate the safety of PBR. Subgroup analysis was also carried out based on BMI, surgical technique (DTI or TSE PBR), proportion of patients receiving preoperative radiotherapy, and follow-up time. This work aims to provide reliable evidence in support of an ideal alternative for breast reconstruction and evaluate the safety of PBR after mastectomies.

\section{METHODS}

\section{Literature search}

Without language restrictions, published articles were searched from English and Chinese databases including PubMed, EMBASE, the Cochrane Library, Web of Science, China National Knowledge Infrastructure (CNKI), and Wan Fang Data Knowledge Service Platform (Wan Fang) from 1 January 2000 to 27 March 2020. The search strategy combined MeSH keywords with text words: "[(prepectoral OR subcutaneous) AND (Mastectomies OR Mastectomy OR Mammaplasty OR Mammaplasties OR 
Mammoplasty OR Mammoplasties OR Breast Reconstruction OR Breast Reconstructions OR Reconstruction, Breast OR Reconstructions, Breast)]". References from selected articles were scrutinized to complement the search.

\section{Selection criteria}

The inclusion criteria were as follows: (1) clinical research; (2) PBR as the surgical method; (3) breast reconstruction as the main research object; (4) clinical data of postoperative complications; (5) consecutive cases; (6) direct reconstruction surgery after mastectomies; and (7) use of ADMs and synthetic meshes. Exclusion criteria were as follows: (1) anatomical knowledge or surgical methods of PBR; (2) animal experiments; (3) letters, abstracts, or reviews; (4) irrelevant studies; (5) ambiguous research findings; (6) inaccessible articles; and (7) fewer than 10 cases in the study. If two or more articles from the same author overlap in the source and duration of the study population, the latest study or the one with the largest sample was included.

\section{Data extraction}

All articles in the initial search were carefully read by two investigators (Guo L and Qian B), using the predetermined inclusion and exclusion criteria to determine eligible studies. A disagreement between the two investigators was resolved through reevaluation of the studies by a third investigator (senior author). All data including name of first author, publication year, country of origin, sample size of breast and patient, mean age, mean BMI, duration of follow-up, history of preoperative radiotherapy, and postoperative complications including hematoma, infection, implant removal, and capsular contracture for included studies were then recorded. The quality of each included study was assessed using the Newcastle-Ottawa scale (NOS) for risk assessment of observational studies in meta-analysis ${ }^{[11]}$.

\section{Statistical analysis}

Data processing software R GUI 3.6.3 was used for statistical analysis of the selected studies. Random effects models were used for all statistical analyses to compensate for differences among included studies. The summary of results was represented using the incidence of events (the ratio of the number of events to the sample size of the breasts) and the $95 \%$ CIs. A 0.5 cell was used to correct the incidence rate and $95 \% \mathrm{CI}$ for studies with a zero-endpoint event. The arcsine transformation method was used to convert the original data to follow a normal distribution. A meta command (analysis of single proportions) was then used to calculate incidence of complications as well as the corresponding 95\%CIs, and the results were presented using forest plots. When a complication was found in more than 10 studies, Funnel plot and Egger regression were used to assess the publication bias $(P<0.05$ was considered as a significant publication bias). In addition, $I^{2}$ statistics and $P$ values were used to evaluate heterogeneity among selected studies $\left(I^{2}<\right.$ $25 \%$ indicates no heterogeneity; 25\%-50\% represents low heterogeneity; 50\%-75\% indicates medium heterogeneity; and $>75 \%$ represents high heterogeneity). To further explore sources of heterogeneity, subgroup analysis was conducted based on BMI $\left(<25 \mathrm{~kg} / \mathrm{m}^{2} v s . \geq 25 \mathrm{~kg} / \mathrm{m}^{2}\right)$, surgical staging (DTI $v s$. TSE PBR), and proportion of patients who had undergone preoperative radiotherapy (0\% vs. $0 \%-100 \%)$. BMI of WHO classification standard was adopted because most of the included studies were conducted in Europe and America. Thus, BMI $\geq 25 \mathrm{~kg} / \mathrm{m}^{2}$ was considered as overweight.

\section{RESULTS}

\section{Literature search}

After a preliminary search of different databases, 1891 articles were retrieved, including 1218 articles from PubMed, 146 articles from EMBASE, 7 articles from the Cochrane Library, 200 articles from Web of Science, 149 articles from CNKI, and 171 articles from Wan Fang. Among the total 1891 retrieved publications, 302 studies were duplicate publications or follow-up studies were repeated and 1385 studies 
were excluded after reading the title and abstract, leaving 204 studies for further evaluation. The full texts of the remaining 204 articles were read to eliminate the studies that did not meet the inclusion criteria. Nineteen studies finally qualified for the present meta-analysis. The flowchart of the literature selection is shown in Figure 1.

\section{Clinical characteristics of included studies}

In total, 1686 patients (2551 breasts) underwent PBR in the included 19 studies. Details for the 19 studies are listed in Supplementary Tables 1 and $2^{[4,12-29]}$, showing that 12, 2, and 5 studies were conducted in the United States, the United Kingdom, and Italy, respectively. The statistics of the various complications in the selected studies are highlighted in Supplementary Tables 2. The quality of each included study was evaluated using NOS scoring criteria. The results presented in Supplementary Tables 1 show that the NOS score ranged from 5 to 7 , and the overall quality was medium ( maximum score $=9$ ).

\section{Main analysis}

Pooled failure and success rates

The implant removal rate (including removal of TE and implant loss) was used to represent the surgical failure rate. According to Figure 2, the implant removal rate was 3.8\% (95\%CI: 2.7\%-5.1\%), and the associated heterogeneity was medium $\left(I^{2}=56 \%, P<0.01\right)$. This means that the failure rate of the operation was $3.8 \%$, while the success rate was $96.2 \%$.

\section{Total complication rate}

As shown in Figure 3, the overall complication rate was $15.4 \%$ (95\%CI: 10.6\%-20.9\%), and a high heterogeneity was observed $\left(I^{2}=84 \%, P<0.01\right)$.

\section{Pooled surgical complication rates}

Based on the included data, three complications are analyzed in detail. First, similar to sub-pectoral breast reconstruction, hematoma also occurred in patients undergoing PBR. According to Supplementary Figure 1, the incidence of this complication was 4.3\% (95\%CI: 2.3\%-6.9\%). Heterogeneity tests showed that $I^{2}=87 \%$ $(P<0.01)$, which indicates a high heterogeneity. Second, Supplementary Figure 2 shows that the incidence of infection was $3.4 \%$ (95\%CI: $2.0 \%-5.1 \%$ ), with a moderate heterogeneity $\left(I^{2}=72 \%, P<0.01\right)$. Third, Supplementary Figure 3 indicates that the capsular contracture rate in nine studies was $0.9 \%$ (95\%CI: 0.1\%$2.6 \%)$ with a high heterogeneity $\left(I^{2}=82 \%, P<0.01\right)$ among the studies.

\section{Publication biases}

According to the funnel plots of various complications shown in Figure 4, the distribution of each study was relatively symmetrical in the triangle. Evaluation of publication bias using Egger's test [Figure 5] revealed no significant publication bias $(P>0.05)$ for the various complications in this study.

\section{Subgroup analysis}

$B M I$

According to Table 1, compared with patients having BMI $<25 \mathrm{~kg} / \mathrm{m}^{2}$, the rate of capsular contracture was lower in patients with $\mathrm{BMI} \geq 25 \mathrm{~kg} / \mathrm{m}^{2}(1.2 \%$ and $0.5 \%$, respectively), which was consistent with the finding that patients with lower weight had a lower rate of capsular contracture ${ }^{[4]}$. Interestingly, other complications led to the opposite result: higher weights in patients were associated with higher rates of surgical complications (hematoma rate, $4.1 \%$ vs. $4.4 \%$; infection rate, $1.3 \%$ vs. $4.8 \%$; and implant removal rate, $2.9 \%$ vs. $4.2 \%$ ), which was contrary to the findings of Casella et al. ${ }^{[4]} \mathrm{A}$ clinical study conducted by Banuelos et al. ${ }^{[14]}$ revealed that obesity increases the risks of incidence of surgical complications and surgical failure. Their findings reveal that, with each one-point increase in BMI, complications and implant removal 


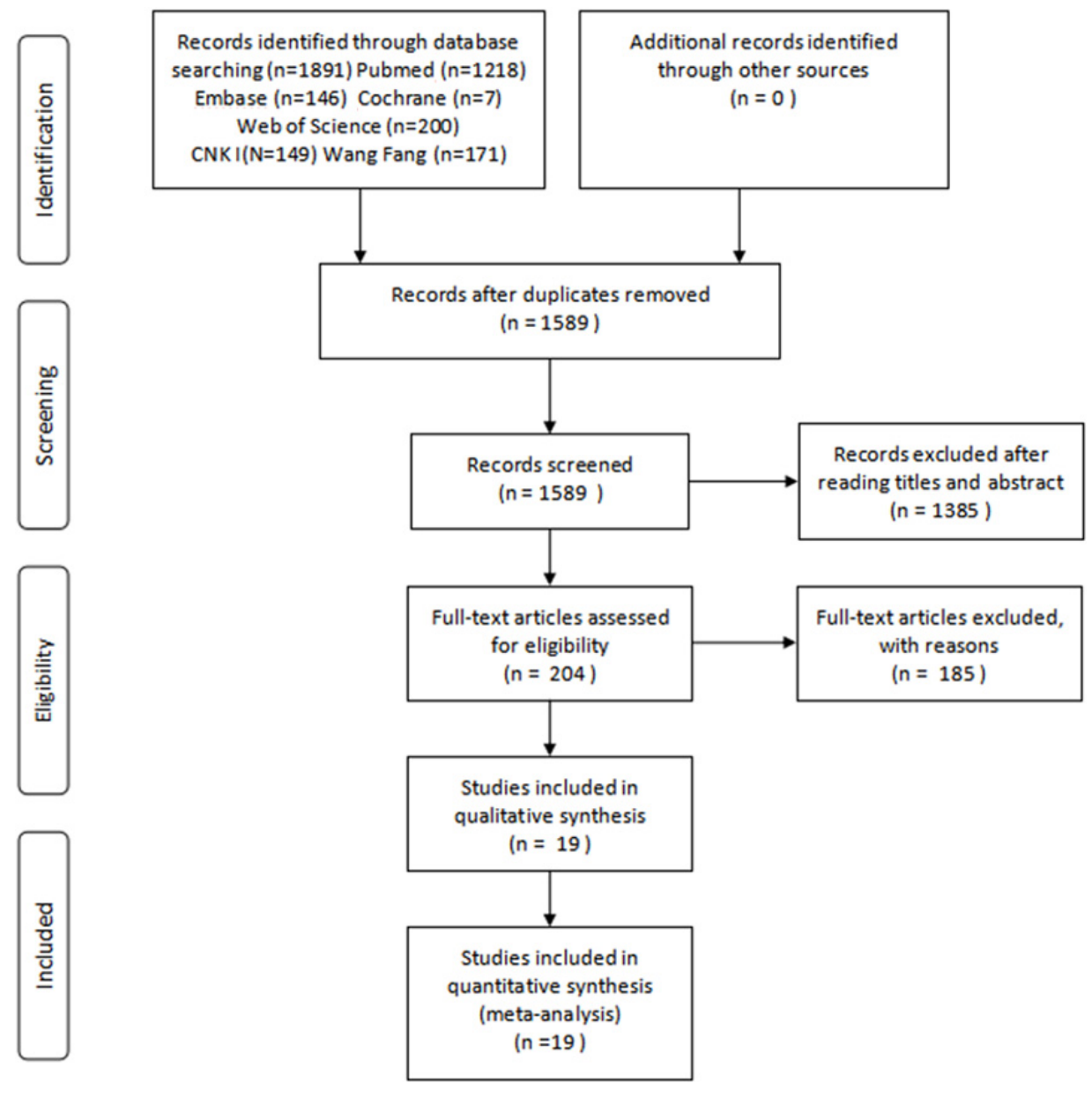

Figure 1. Flowchart of the literature search and selection.

rates increased by $3.4 \%$ and $8.6 \%$, respectively. However, the study did not consider obesity as a contraindication of PBR. The various complications of patients with BMI $<35 \mathrm{~kg} / \mathrm{m}^{2}$ and BMI $>35 \mathrm{~kg} / \mathrm{m}^{2}$ were as follows: hematoma rate, $7.6 \%$ vs. $10.3 \%$; infection rate, $5.3 \%$ vs. $13.8 \%$; and implant removal rate, $4.6 \%$ vs. $10.3 \%$.

\section{Surgical technique}

The incidence of various complications was lower in patients who received DTI PBR compared to those who underwent TSE PBR (implant removal rate, $2.8 \%$ vs. 5.8\%; hematoma rate, $2.4 \%$ vs. $7.6 \%$; infection rate, $2.1 \%$ vs. 5.9\%; capsular contracture rate, $0.9 \%$ vs. $1.1 \%$; and total complication rate, $8.5 \%$ vs. $21.3 \%$ ). Casella et al. ${ }^{[4]}$ reported the same conclusion (total complication rate, $22.1 \%$ vs. $23.1 \%$; implant removal rate, $2.5 \%$ vs. $3.8 \%$; hematoma rate, $1.1 \%$ vs. $1.3 \%$; and capsular contracture rate, $3.5 \%$ vs. $3.8 \%$ ). In the subgroup analysis, heterogeneity of one or two groups was reduced by varying degrees in each complication, indicating that the surgical technique causes heterogeneity in the incidence of various complications.

\section{Preoperative radiotherapy}

The current meta-analysis showed that patients undergoing preoperative radiotherapy are at a higher risk of various complications. The incidences of all complications studied were lower in patients who did not undergo preoperative radiotherapy (no preoperative radiotherapy $v$ s. preoperative radiotherapy: hematoma 


$\begin{array}{lrrrrrrr}\text { Study } & \text { Events Total } & \text { Proportion } & \text { 95\%-Cl } \begin{array}{r}\text { Weight } \\ \text { (fixed) }\end{array} \text { Weight } \\ \text { (random) }\end{array}$

Figure 2. Forest plot of the pooled implant removal rate after surgery. The size of each square is proportional to the study's weight. Horizontal lines indicate the $95 \% \mathrm{Cl}$. Diamonds indicate the pooled incidence rate with its corresponding $95 \% \mathrm{Cl}$.

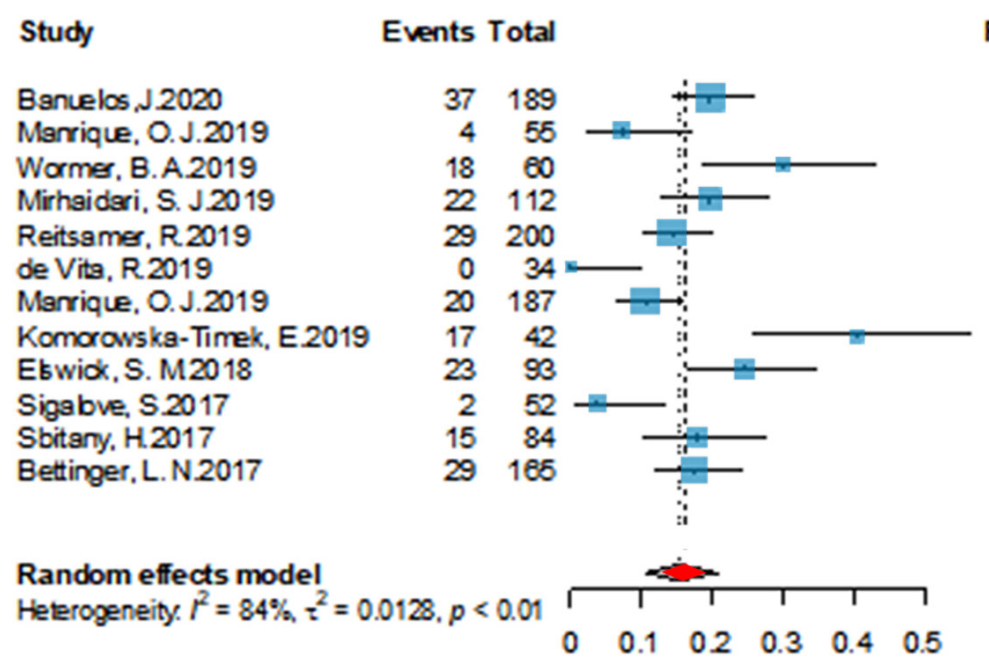

\begin{tabular}{|c|c|c|c|}
\hline Proportion & $95 \%-\mathrm{Cl}$ & $\begin{array}{r}\text { Weight } \\
\text { (fixed) }\end{array}$ & $\begin{array}{r}\text { Weight } \\
\text { (random) }\end{array}$ \\
\hline $\begin{array}{l}0.196 \\
0.073\end{array}$ & $\begin{array}{l}{[0.142 ; 0.260]} \\
{[0.020 ; 0.176]}\end{array}$ & $\begin{array}{r}14.8 \% \\
4.3 \%\end{array}$ & $\begin{array}{l}9.4 \% \\
7.7 \%\end{array}$ \\
\hline $\begin{array}{l}0.300 \\
0.196\end{array}$ & $\begin{array}{l}{[0.188 ; 0.432]} \\
{[0.127 ; 0.282}\end{array}$ & $\begin{array}{l}4.7 \% \\
8.8 \%\end{array}$ & $\begin{array}{l}7.8 \% \\
8.8 \%\end{array}$ \\
\hline $\begin{array}{l}0.145 \\
0.000 \\
0.107\end{array}$ & $\begin{array}{l}{[0.099,0.202]} \\
{[0.000 ; 0.103]} \\
{[0.067 ; 0.160]}\end{array}$ & $\begin{array}{r}15.7 \% \\
2.7 \% \\
14.7 \%\end{array}$ & $\begin{array}{l}9.4 \% \\
6.6 \% \\
9.4 \%\end{array}$ \\
\hline $\begin{array}{l}0.405 \\
0.247\end{array}$ & $\begin{array}{l}{[0.258 ; 0.587]} \\
{[0.164 ; 0.348]}\end{array}$ & $\begin{array}{l}3.3 \% \\
7.3 \%\end{array}$ & $\begin{array}{l}7.1 \% \\
8.6 \%\end{array}$ \\
\hline $\begin{array}{l}0.038 \\
0.179 \\
0.178\end{array}$ & $\begin{array}{l}{[0.005 ; 0.132]} \\
{[0.104 ; 0.277]} \\
{[0.121 ; 0.243]}\end{array}$ & $\begin{array}{r}4.1 \% \\
6.6 \% \\
13.0 \%\end{array}$ & $\begin{array}{l}7.5 \% \\
8.4 \% \\
9.3 \%\end{array}$ \\
\hline 0.154 & {$[0.106 ; 0.209]$} & & $100.0 \%$ \\
\hline
\end{tabular}

Figure 3. Forest plot of the pooled total complication rate after surgery. The size of each square is proportional to the study's weight. Horizontal lines indicate the $95 \% \mathrm{Cl}$. Diamonds indicate the pooled incidence rate with its corresponding $95 \% \mathrm{Cl}$.

rate, $2.1 \%$ vs. $7.4 \%$; infection rate, $0.8 \%$ vs. 5.4\%; implant removal rate, $3.9 \%$ vs. 4.6\%; capsular contracture rate, $0.2 \%$ vs. $2.0 \%$; and total complication rate, $15.2 \%$ vs. $19.8 \%$ ). A clinical study by Reitsamer et al. ${ }^{[16]}$ revealed that the various complication rates associated with no preoperative radiotherapy and preoperative radiotherapy were as follows: hematoma rate, $3.4 \%$ vs. $3.8 \%$; and implant removal rate, $3.4 \%$ vs. $3.8 \%$. 

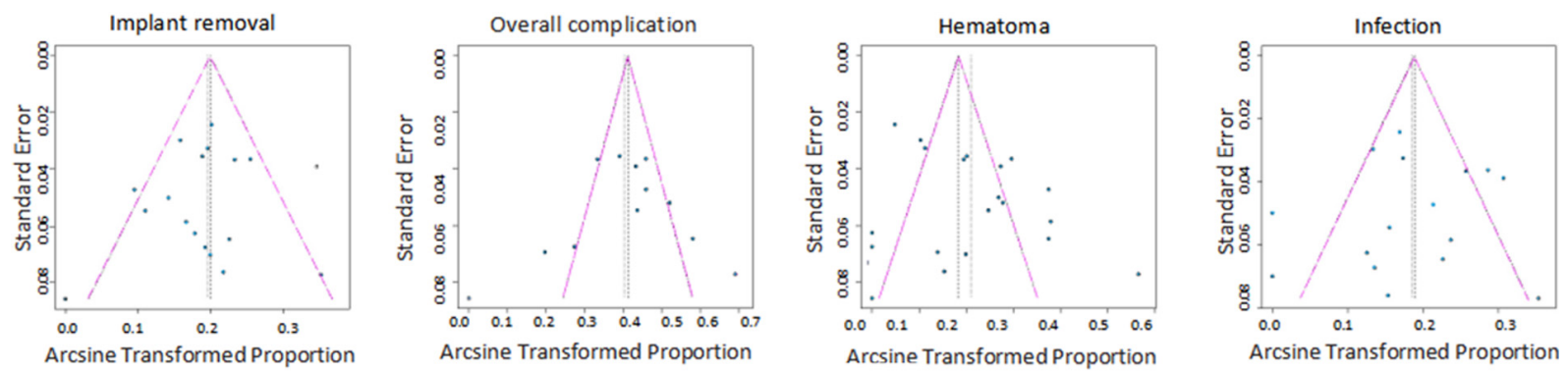

Figure 4. Funnel plots for the various complications. Each circle represents an identified study.
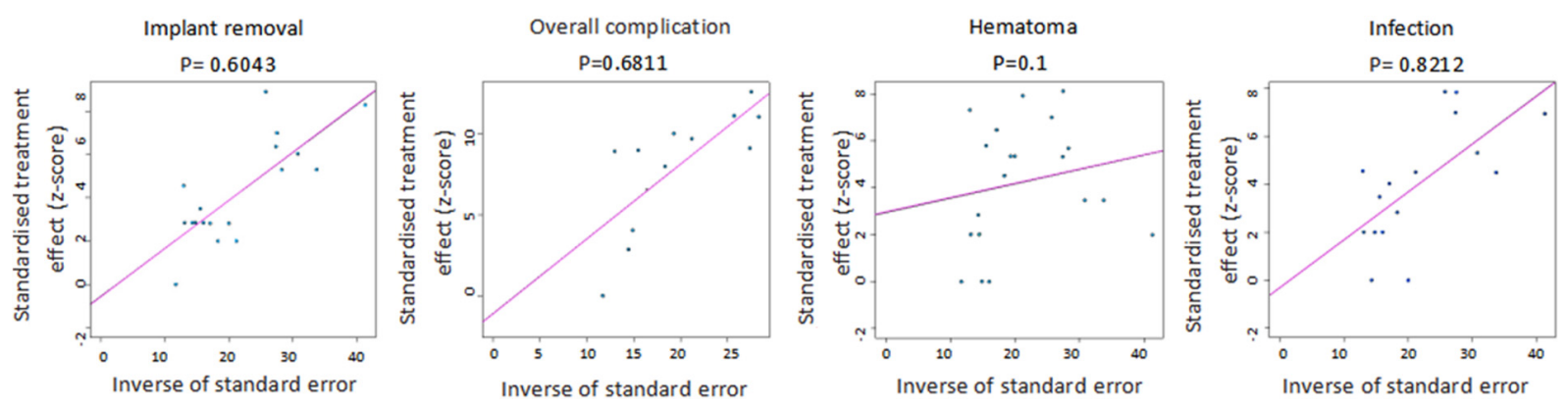

Figure 5. Linear regression test of funnel plot asymmetry. Each circle represents an identified study.

Follow-up

With the prolongation of follow-up time, the incidence of long-term complications, such as capsular contracture and implant removal increased $(<12$ months $v s . \geq 12$ months: implant removal rate, $3.3 \% v s$. $3.9 \%$; and capsular contracture rate, $1.1 \%$ vs. $0 \%)$. Interestingly, when the follow-up time was short $(<12$ months), the incidence of short-term complications such as hematoma and infection was higher $(<12$ months $v s . \geq 12$ months: hematoma rate, $7.1 \%$ vs. $3.6 \%$; and infection rate, $3.1 \%$ vs. $4.5 \%$ ).

\section{DISCUSSION}

Implant-based PBR was first described by Snyderman and Guthrie ${ }^{[30]}$ in the early 1970s. PBR is simple and preserves the integrity of the pectoralis muscle. Unfortunately, skin flap necrosis leads to a high reconstruction failure rate. Schlenker et al. ${ }^{[3]]}$ described that PBR has a higher complication rate, e.g., capsular contracture in $56 \%$, necrosis rate in $13.5 \%$, and implant removal in $28 \%$ of cases. Due to the high complication rate, PBR has been abandoned for decades. Sub-pectoral breast reconstruction provides the best implant coverage and reduces complication rates ${ }^{[32]}$. With the application of ADMs as well as synthetic meshes and the introduction of skin-sparing mastectomies, surgeons prefer to perform $\mathrm{PBR}^{[33-35]}$. The surgical method of the included studies is PBR with ADMs and synthetic meshes. Compared to the traditional sub-pectoral breast reconstruction, PBR offers the following advantages: shorter operation time, simple operation, faster recovery, and minimal postoperative pain ${ }^{[36-40]}$. In addition, since the prosthesis is placed in the front of the pectoralis major muscle, animation deformity caused by movement of pectoralis major muscle is eliminated, leading to an improved aesthetic effect ${ }^{[41,42]}$.

The results of the present work demonstrate that PBR is safe and reliable, which is supported by its low surgical failure rate (3.8\%) and low complication rates (total complication rate, 15.4\%; hematoma rate, 4.3\%; infection rate, 3.4\%; and capsular contracture rate, $0.9 \%$ ). A study conducted by Manrique et al. ${ }^{[12]}$ indicated that PBR did not increase the incidence of various complications compared to sub-pectoral breast 
Table 1. Subgroup analysis of incidence rates of various complications

\begin{tabular}{|c|c|c|c|c|c|c|}
\hline Complication & & Implant removal & Total complications & Hematoma & Infection & Capsular contractur \\
\hline \multicolumn{7}{|l|}{ BMI $\left(\mathrm{kg} / \mathrm{m}^{2}\right)$} \\
\hline \multirow[t]{2}{*}{ Events } & $<25$ & 22 & - & 25 & 16 & 19 \\
\hline & $\geq 25$ & 81 & - & 93 & 72 & 23 \\
\hline \multirow[t]{2}{*}{ Total } & $<25$ & 745 & - & 745 & 745 & 645 \\
\hline & $\geq 25$ & 1661 & - & 1806 & 1427 & 722 \\
\hline \multirow[t]{2}{*}{$R(95 \% \mathrm{Cl})$} & $<25$ & $0.029(0.018-0.042)$ & - & $0.041(0.012-0.088)$ & $0.013(0.002-0.036)$ & $0.012(0.000-0.042)$ \\
\hline & $\geq 25$ & $0.042(0.026-0.061)$ & - & $0.044(0.019-0.077)$ & $0.048(0.031-0.067)$ & $0.005(0.000-0.035)$ \\
\hline \multirow[t]{2}{*}{$P$ value } & $<25$ & 0.86 & - & $<0.01$ & $<0.01$ & $<0.01$ \\
\hline & $\geq 25$ & $<0.01$ & - & $<0.01$ & 0.01 & $<0.01$ \\
\hline \multirow[t]{2}{*}{$l^{2}(\%)$} & $<25$ & 1 & - & 84 & 74 & 80 \\
\hline & $\geq 25$ & 65 & - & 88 & 56 & 87 \\
\hline \multicolumn{7}{|l|}{ Stage } \\
\hline \multirow[t]{2}{*}{ Events } & DTI & 42 & 55 & 53 & 29 & 32 \\
\hline & TSE & 59 & 159 & 62 & 59 & 10 \\
\hline Total & DTI & 1391 & 401 & 1391 & 1157 & 902 \\
\hline \multirow[t]{2}{*}{$R(95 \% \mathrm{Cl})$} & DTI & $0.028(0.020-0.038)$ & $0.085(0.020-0.188)$ & $0.024(0.005-0.057)$ & $0.021(0.010-0.036)$ & $0.009(0.000-0.038)$ \\
\hline & TSE & $0.058(0.034-0.087)$ & $0.213(0.155-0.276)$ & $0.076(0.040-0.122)$ & $0.059(0.038-0.085)$ & $0.011(0.000-0.049)$ \\
\hline \multirow[t]{2}{*}{$P$ value } & DTI & 0.40 & $<0.01$ & $<0.01$ & 0.05 & $<0.01$ \\
\hline & TSE & 0.03 & $<0.01$ & $<0.01$ & 0.04 & $<0.01$ \\
\hline \multirow[t]{2}{*}{$l^{2}(\%)$} & DTI & 4 & 88 & 89 & 50 & 86 \\
\hline & TSE & 65 & 77 & 83 & 56 & 80 \\
\hline \multicolumn{7}{|c|}{ Preoperative radiotherapy } \\
\hline \multirow[t]{2}{*}{ Events } & 0 & 20 & 27 & 15 & 3 & 1 \\
\hline & $0-100$ & 61 & 148 & 94 & 71 & 19 \\
\hline \multirow[t]{2}{*}{ Total } & 0 & 481 & 172 & 355 & 262 & 212 \\
\hline & $0-100$ & 1330 & 955 & 1549 & 1349 & 594 \\
\hline \multirow[t]{2}{*}{$R(95 \% \mathrm{Cl})$} & 0 & $0.039(0.024-0.059)$ & $0.152(0.025-0.359)$ & $0.021(0.000-0.070)$ & $0.008(0.000-0.028)$ & $0.002(0.000-0.0013)$ \\
\hline & $0-100$ & $0.046(0.027-0.070)$ & $0.198(0.146-0.255)$ & $0.074(0.040-0.118)$ & $0.054(0.035-0.077)$ & $0.020(0.002-0.054)$ \\
\hline \multirow[t]{2}{*}{$P$ value } & 0 & 0.39 & $<0.01$ & $<0.01$ & 0.20 & 0.32 \\
\hline & $0-100$ & $<0.01$ & $<0.01$ & $<0.01$ & $<0.01$ & 0.02 \\
\hline
\end{tabular}




\begin{tabular}{|c|c|c|c|c|c|c|}
\hline \multirow[t]{2}{*}{$f^{2}(\%)$} & 0 & 2 & 88 & 82 & 36 & 11 \\
\hline & $0-100$ & 68 & 77 & 88 & 65 & 79 \\
\hline \multicolumn{7}{|l|}{ Follow-up } \\
\hline \multirow[t]{2}{*}{ Events } & $<12$ & 50 & 26 & 11 & 11 & 0 \\
\hline & $\geq 12$ & 166 & 92 & 77 & 92 & 42 \\
\hline \multirow[t]{2}{*}{ Total } & $<12$ & 220 & 263 & 229 & 263 & 1283 \\
\hline & $\geq 12$ & 1053 & 2288 & 1943 & 2143 & 84 \\
\hline \multirow[t]{2}{*}{$R(95 \% \mathrm{Cl})$} & $<12$ & $0.174(0.032-0.396)$ & $0.071(0.011-0.179)$ & $0.045(0.017-0.087)$ & $0.033(0.006-0.081)$ & $0.011(0.001-0.030)$ \\
\hline & $\geq 12$ & $0.146(0.107-0.191)$ & $0.036(0.018-0.062)$ & $0.031(0.016-0.050)$ & $0.039(0.028-0.053)$ & $0.000(0.000-0.011)$ \\
\hline \multirow[t]{2}{*}{$P$ value } & $<12$ & $<0.01$ & $<0.01$ & 0.17 & $<0.01$ & $<0.01$ \\
\hline & $\geq 12$ & $<0.01$ & $<0.01$ & $<0.01$ & $<0.01$ & - \\
\hline
\end{tabular}

DTI: Direct to-implant; TSE: two-stage expander-assisted.

reconstruction (the total complications rate, $7.2 \%$ vs. $11.6 \%$; implant removal rate, $3.6 \%$ vs. $1.5 \%$; hematoma rate, $0 \%$ vs. $5.8 \%$; infection rate, $1.8 \%$ vs. $1.5 \%$; and capsular contracture rate, $0 \%$ vs. $2.9 \%$ ), which is consistent with several other clinical studies ${ }^{[12,15,43,44]}$. The overall complication rate in the current meta-analysis was only $15.4 \%$ (95\%CI: $10.6 \%-20.9 \%)$. In a previous long-term study ${ }^{[18]}$, the total complication rates of prepectoral and subpectoral breast reconstruction were $10.7 \%$ and $15.4 \%$, respectively, indicating PBR does not significantly increase the risk of total surgical complications. In addition, the capsular contracture rate was only 0.9\% (95\%CI: $0.1 \%-2.6 \%)$ in the current meta-analysis. Similarly, Komorowska-Timek et al. ${ }^{[20]}$ demonstrated PBR could greatly reduce the incidence of capsular contracture due to its low capsular contracture rate (2.7\%) compared to that of sub-pectoral reconstruction procedures (15.6\%).

Based on the subgroup analysis, the following conclusions can be drawn to provide directions for further research, although their accuracy cannot be determined because it may be affected by confounding bias factors. (1) Patients with higher weight are less likely to suffer capsular contracture, but they are prone to other complications. However, Banuelos et al. ${ }^{[14]}$ stated obesity should not be a contraindication for PBR, since, for patients with BMI $>35 \mathrm{~kg} / \mathrm{m}^{2}$, pectoralis major muscle had no protective effect in breast reconstruction. Meanwhile, for obese patients, PBR has a high surgical success rate (>95\%), alleviates post-surgery pain, and has a lower risk of animation deformity ${ }^{[14]}$. To reduce the incidence of complications of obese patients who underwent PBR, indocyanine green angiography to detect the blood perfusion of the flap, intraoperative air expansion to reduce the pressure on the flap, and antibiotics to prevent postoperative infection were used ${ }^{[4,14]}$. (2) The incidence of various complications was lower in patients who underwent DTI PBR compared to the case of TSE PBR. The following speculations were made in the current study. First, single-stage breast reconstruction is simple and could maintain relatively normal tissue anatomy ${ }^{[4,45-47]}$. Second, studies have shown that the implantation of a tissue expander is related to high incidences of most complications, including flap necrosis, implant loss, and capsular contracture ${ }^{[48,49,50]}$. (3) Preoperative radiotherapy may be a risk factor for increasing the incidence of various complications $^{[51]}$. Reconstruction surgery among patients who receive preoperative radiotherapy can result in edema, inflammation, and desquamation of 
breast tissue and skin in the short term (several weeks) ${ }^{[2-57]}$. Comparatively, in the long-term (months to years) follow up, fibrotic tissue caused by radiation deposits in the skin and muscles may lead to thickening of the dermis, fibrosis, and atrophy of muscles. These delayed side effects of radiotherapy can result in more late-stage complications such as capsular contracture, delayed healing, infections, and compression ${ }^{[52-57]}$. In a study of 479 patients who received subpectoral breast reconstruction at the Massachusetts General Hospital, the rate of complications $(41.1 \%)$ was markedly higher in those who had received preoperative radiation compared to the patients without preoperative radiation ${ }^{[58]}$. (4) Since most of the included studies are retrospective studies, with the extension of follow-up time, data collection of short-term complications is more prone to recall and follow-up bias. Hess ${ }^{[5]}$ also elaborated on this point.

Taken together, the results show that the complications analyzed in the current meta-analysis were comprehensive. The NOS shows that the difference in experimental design between the various studies is not large, so it has little effect on the results of this study. Many studies were included, and the analysis had a wide range of people. Although each complication exhibited moderate or high heterogeneity, subgroup analysis was performed for each complication, including BMI, surgical staging (DTI or TSE PBR), and the proportion of patients receiving preoperative radiotherapy to explore the source of heterogeneity and the impact of these factors on the incidence of surgical complications. However, the current study has some limitations. First, subgroup analysis of other risk factors such as implant's size, whether patients were smokers, whether patients had comorbidities (diabetes, heart disease, and hyperlipidemia), and whether patients received postoperative chemotherapy were not performed. Second, since the included studies are non-randomized controlled, the results of the study are affected by confounding bias factors, although efforts were made to minimize the effects of these factors. Third, due to the lack of data related to aesthetic complications in most of the studies reviewed, statistical analysis of aesthetic complications could not be performed. Future studies should incorporate large sample and standardized parameters to reduce the impact of these factors on statistical analysis results, thereby improving the quality of the scientific studies.

In conclusion, the results of this single-arm meta-analysis show that PBR may be a safe and reliable operation with a high success rate. The total complications associated with PBR did not increase significantly, and the rate of capsular contracture decreased significantly. However, PBR could be an alternative to sub-pectoral breast reconstruction. In additional, the rate of capsular contracture was higher in patients with lower weight, but the incidence of other complications showed the opposite results. Compared with patients who received TSE PBR, those who underwent DTI PBR had lower incidences of surgical complications. Preoperative radiotherapy was found to be a risk factor for increasing the various postoperative complications. Additionally, large sample and multicenter studies with standardized reports of perioperative parameters and clinical outcomes are needed for further evaluation in the future.

\section{DECLARATIONS}

\section{Acknowledgements}

The authors thank Professor Xiaoling Feng for her comments and linguistic advice.

\section{Authors' contributions}

Made substantial contributions to conception and design of the study and performed data analysis and interpretation: Guo L, Liu J, Qian B, Feng X

Performed data acquisition, as well as provided administrative, technical, and material support: Sun J, Xia Y, Guo N, An R, Guo K 


\section{Availability of data and materials}

Published articles were searched from English and Chinese databases including PubMed, EMBASE, the Cochrane Library, Web of Science, China National Knowledge Infrastructure (CNKI), Wan Fang Data Knowledge Service Platform (Wan Fang).

\section{Financial support and sponsorship}

This work was supported by the National Key R\&D Program of China (2019YFA0110500), the National Natural Science Foundation of China (No.81873941 to Jiaming Sun, No.81901977 to Ran An, No.81701912 to Yun Xia) and Natural Science Foundation of Hubei Province (No.2016CFB133 to Ke Guo, No.2019CFB561 to Nengqiang Guo).

\section{Conflicts of interest}

All authors declare that there are no conflicts of interest.

\section{Ethical approval and consent to participate}

Not applicable.

\section{Consent for publication}

Not applicable.

\section{Copyright}

(c) The Author(s) 2021.

\section{REFERENCES}

1. Wörmann B. Breast cancer: basics, screening, diagnostics and treatment. Med Monatsschr Pharm 2017;40:55-64. PubMed

2. Scheflan M, Colwell AS. Tissue reinforcement in implant-based breast reconstruction. Plast Reconstr Surg Glob Open $2014 ; 2$ :e192. DOI PubMed PMC

3. Ricci JA, Treiser MD, Tao R, et al. Predictors of complications and comparison of outcomes using surgi mend fetal bovine and alloDerm human cadaveric acellular dermal matrices in implant-based breast reconstruction. Plast Reconstr Surg 2016;138:583e-91e. DOI PubMed

4. Casella D, Di Taranto G, Onesti MG, Greco M, Ribuffo D. A retrospective comparative analysis of risk factors and outcomes in directto-implant and two-stages prepectoral breast reconstruction: BMI and radiotherapy as new selection criteria of patients. Eur J Surg Oncol 2019;45:1357-63. DOI PubMed

5. Walia GS, Aston J, Bello R, et al. Prepectoral versus subpectoral tissue expander placement: a clinical and quality of life outcomes study. Plast Reconstr Surg Glob Open 2018;6:e1731. DOI PubMed PMC

6. Zhu L, Mohan AT, Abdelsattar JM, et al. Comparison of subcutaneous versus submuscular expander placement in the first stage of immediate breast reconstruction. J Plast Reconstr Aesthet Surg 2016;69:e77-86. DOI PubMed

7. Casella D, Bernini M, Bencini L, et al. TiLoop ${ }^{\circledR}$ Bra mesh used for immediate breast reconstruction: comparison of retropectoral and subcutaneous implant placement in a prospective single-institution series. Eur J Plast Surg 2014;37:599-604. DOI PubMed PMC

8. Casella D, Di Taranto G, Marcasciano M, et al. Nipple-sparing bilateral prophylactic mastectomy and immediate reconstruction with TiLoop ${ }^{\circledR}$ Bra mesh in BRCA1/2 mutation carriers: A prospective study of long-term and patient reported outcomes using the BREAST-Q. Breast 2018;39:8-13. DOI PubMed

9. Grieco MP, Simonacci F, Bertozzi N, Grignaffini E, Raposio E. Breast reconstruction with breast implants. Acta Biomed 2019;89:45762. DOI PubMed PMC

10. Spear SL, Baker JL, Coffee HH. Classification of capsular contracture after prosthetic breast reconstruction. Plast Reconstr Surg 1995;96:1124. PubMed

11. Stang A. Critical evaluation of the Newcastle-Ottawa scale for the assessment of the quality of nonrandomized studies in metaanalyses. Eur J Epidemiol 2010;25:603-5. DOI PubMed

12. Manrique OJ, Kapoor T, Banuelos J, et al. Single-stage direct-to-implant breast reconstruction: a comparison between subpectoral versus prepectoral implant placement. Ann Plast Surg 2020;84:361-5. DOI PubMed

13. Mirhaidari SJ, Azouz V, Wagner DS. Prepectoral versus subpectoral direct to implant immediate breast reconstruction. Ann Plast Surg 2020;84:263-70. DOI PubMed

14. Banuelos J, Abu-Ghname A, Vyas K, et al. Should obesity be considered a contraindication for prepectoral breast reconstruction? Plast Reconstr Surg 2020;145:619-27. DOI PubMed

15. Wormer BA, Valmadrid AC, Ganesh Kumar N, et al. Reducing expansion visits in immediate implant-based breast reconstruction: a comparative study of prepectoral and subpectoral expander placement. Plast Reconstr Surg 2019;144:276-86. DOI PubMed 
16. Reitsamer R, Peintinger F, Klaassen-Federspiel F, Sir A. Prepectoral direct-to-implant breast reconstruction with complete ADM or synthetic mesh coverage - 36-Months follow-up in 200 reconstructed breasts. Breast 2019;48:32-7. DOI PubMed

17. Vita R, Buccheri EM, Villanucci A, Pozzi M. Breast reconstruction actualized in nipple-sparing mastectomy and direct-to-implant, prepectoral polyurethane positioning: early experience and preliminary results. Clin Breast Cancer 2019;19:e358-63. DOI PubMed

18. Manrique OJ, Banuelos J, Abu-Ghname A, et al. Surgical outcomes of prepectoral versus subpectoral implant-based breast reconstruction in young women. Plast Reconstr Surg Glob Open 2019;7:e2119. DOI PubMed PMC

19. Gardani M, Simonacci F, De Sario G, Cattadori F, Raposio E, Palli D. Prepectoral breast reconstruction using the Braxon® porcine acellular dermal matrix: a retrospective study. Eur J Plast Surg 2019;42:145-54. DOI

20. Komorowska-Timek E, Merrifield B, Turfe Z, Davis AT. Subcutaneous prosthetic breast reconstructions following skin reduction mastectomy. Plast Reconstr Surg Glob Open 2019;7:e2078. DOI PubMed PMC

21. Sinnott CJ, Persing SM, Pronovost M, Hodyl C, McConnell D, Ott Young A. Impact of postmastectomy radiation therapy in prepectoral versus subpectoral implant-based breast reconstruction. Ann Surg Oncol 2018;25:2899-908. DOI PubMed

22. Baker BG, Irri R, MacCallum V, Chattopadhyay R, Murphy J, Harvey JR. A prospective comparison of short-term outcomes of subpectoral and prepectoral strattice-based immediate breast reconstruction. Plast Reconstr Surg 2018;141:1077-84. DOI PubMed

23. Elswick SM, Harless CA, Bishop SN, et al. Prepectoral implant-based breast reconstruction with postmastectomy radiation therapy. Plast Reconstr Surg 2018;142:1-12. DOI PubMed

24. Bettinger LN, Waters LM, Reese SW, Kutner SE, Jacobs DI. Comparative study of prepectoral and subpectoral expander-based breast reconstruction and clavien IIIb score outcomes. Plast Reconstr Surg Glob Open 2017;5:e1433. DOI PubMed PMC

25. Jones G, Yoo A, King V, et al. Prepectoral immediate direct-to-implant breast reconstruction with anterior AlloDerm coverage. Plast Reconstr Surg 2017;140:31S-8S. DOI PubMed

26. Vidya R, Masià $\mathrm{J}$, Cawthorn $\mathrm{S}$, et al. Evaluation of the effectiveness of the prepectoral breast reconstruction with Braxon dermal matrix: First multicenter European report on 100 cases. Breast $J$ 2017;23:670-6. DOI PubMed

27. Onesti MG, Maruccia M, Di Taranto G, et al. Clinical, histological, and ultrasound follow-up of breast reconstruction with one-stage muscle-sparing "wrap" technique: A single-center experience. J Plast Reconstr Aesthet Surg 2017;70:1527-36. DOI PubMed

28. Sigalove S, Maxwell GP, Sigalove NM, et al. Prepectoral implant-based breast reconstruction and postmastectomy radiotherapy: shortterm outcomes. Plast Reconstr Surg Glob Open 2017;5:e1631. DOI PubMed PMC

29. Sbitany H, Piper M, Lentz R. Prepectoral breast reconstruction: a safe alternative to submuscular prosthetic reconstruction following nipple-Sparing Mastectomy. Plast Reconstr Surg 2017;140:432-43. DOI PubMed

30. Snyderman RK, Guthrie RH. Reconstruction of the female breast following radical mastectomy. Plast Reconstr Surg 1971;47:565-7. DOI PubMed

31. Schlenker JD, Bueno RA, Ricketson G, Lynch JB. Loss of silicone implants after subcutaneous mastectomy and reconstruction. Plast Reconstr Surg 1978;62:853-61. DOI PubMed

32. Spear SL, Majidian A. Immediate breast reconstruction in two stages using textured, integrated-valve tissue expanders and breast implants: a retrospective review of 171 consecutive breast reconstructions from 1989 to 1996. Plast Reconstr Surg 1998;101:53-63. DOI PubMed

33. Breuing KH, Warren SM. Immediate bilateral breast reconstruction with implants and inferolateral AlloDerm slings. Ann Plast Surg 2005;55:232-9. DOI PubMed

34. Dieterich M, Dieterich H, Timme S, Reimer T, Gerber B, Stubert J. Using a titanium-coated polypropylene mesh (TiLOOP® Bra) for implant-based breast reconstruction: case report and histological analysis. Arch Gynecol Obstet 2012;286:273-6. DOI PubMed

35. Pittman TA, Abbate OA, Economides JM. The P1 method: prepectoral breast reconstruction to minimize the palpable implant edge and upper pole rippling. Ann Plast Surg 2018;80:487-92. DOI PubMed

36. Clemens MW, Kronowitz SJ. Acellular dermal matrix in irradiated tissue expander/implant-based breast reconstruction: evidencebased review. Plast Reconstr Surg 2012;130:27S-34S. DOI PubMed

37. Basu CB, Jeffers L. The role of acellular dermal matrices in capsular contracture: a review of the evidence. Plast Reconstr Surg 2012;130:118S-24S. DOI PubMed

38. Spear SL, Parikh PM, Reisin E, Menon NG. Acellular dermis-assisted breast reconstruction. Aesthetic Plast Surg 2008;32:418-25. DOI PubMed

39. Vardanian AJ, Clayton JL, Roostaeian J, et al. Comparison of implant-based immediate breast reconstruction with and without acellular dermal matrix. Plast Reconstr Surg 2011;128:403e-10e. DOI PubMed

40. Spear SL, Schwartz J, Dayan JH, Clemens MW. Outcome assessment of breast distortion following submuscular breast augmentation. Aesthetic Plast Surg 2009;33:44-8. DOI PubMed

41. Haan A, Toor A, Hage JJ, Veeger HE, Woerdeman LA. Function of the pectoralis major muscle after combined skin-sparing mastectomy and immediate reconstruction by subpectoral implantation of a prosthesis. Ann Plast Surg 2007;59:605-10. DOI PubMed

42. Scheflan M, Colwell AS. Tissue reinforcement in implant-based breast reconstruction. Plast Reconstr Surg Glob Open 2014;2:e192. DOI PubMed PMC

43. Walia GS, Aston J, Bello R, et al. Prepectoral versus subpectoral tissue expander placement: a clinical and quality of life outcomes study. Plast Reconstr Surg Glob Open 2018;6:e1731. DOI PubMed PMC

44. Sobti N, Weitzman RE, Nealon KP, et al. Evaluation of capsular contracture following immediate prepectoral versus subpectoral direct-to-implant breast reconstruction. Sci Rep 2020;10:1137. DOI PubMed PMC

45. Janhofer DE, Economides JM, Song DH. The suture tab technique: securing implant position in prepectoral breast reconstruction. Plast Reconstr Surg Glob Open 2018;6:e2005. DOI PubMed PMC 
46. Blacam C, Momoh AO, Colakoglu S, Slavin SA, Tobias AM, Lee BT. Cost analysis of implant-based breast reconstruction with acellular dermal matrix. Ann Plast Surg 2012;69:516-20. DOI PubMed

47. Jansen LA, Macadam SA. The use of AlloDerm in postmastectomy alloplastic breast reconstruction: part II. A cost analysis. Plast Reconstr Surg 2011;127:2245-54. DOI PubMed

48. Vandeweyer E, Deraemaecker R. Radiation therapy after immediate breast reconstruction with implants. Plast Reconstr Surg 2000;106:56-8; discussion 59. DOI PubMed

49. Forman DL, Chiu J, Restifo RJ, Ward BA, Haffty B, Ariyan S. Breast reconstruction in previously irradiated patients using tissue expanders and implants: a potentially unfavorable result. Ann Plast Surg 1998;40:360-3; discussion 363. DOI PubMed

50. Colwell AS, Damjanovic B, Zahedi B, Medford-Davis L, Hertl C, Austen WG Jr. Retrospective review of 331 consecutive immediate single-stage implant reconstructions with acellular dermal matrix: indications, complications, trends, and costs. Plast Reconstr Surg 2011;128:1170-8. DOI PubMed

51. Berry T, Brooks S, Sydow N, et al. Complication rates of radiation on tissue expander and autologous tissue breast reconstruction. Ann Surg Oncol 2010;17 Suppl 3:202-10. DOI PubMed

52. Clemens MW, Kronowitz SJ. Acellular dermal matrix in irradiated tissue expander/implant-based breast reconstruction: evidencebased review. Plast Reconstr Surg 2012;130:27S-34S. DOI PubMed

53. Radovan C. Breast reconstruction after mastectomy using the temporary expander. Plast Reconstr Surg 1982;69:195-208. DOI PubMed

54. Lapin R, Elliott M, Juri H. The use of an integral tissue expander for primary breast reconstruction. Aesthetic Plast Surg 1985;9:221-6. DOI PubMed

55. Magill LJ, Robertson FP, Jell G, Mosahebi A, Keshtgar M. Determining the outcomes of post-mastectomy radiation therapy delivered to the definitive implant in patients undergoing one- and two-stage implant-based breast reconstruction: a systematic review and metaanalysis. J Plast Reconstr Aesthet Surg 2017;70:1329-35. DOI PubMed

56. Clemens MW, Kronowitz SJ. Current perspectives on radiation therapy in autologous and prosthetic breast reconstruction. Gland Surg 2015;4:222-31. DOI PubMed PMC

57. Lam TC, Hsieh F, Boyages J. The effects of postmastectomy adjuvant radiotherapy on immediate two-stage prosthetic breast reconstruction: a systematic review. Plast Reconstr Surg 2013;132:511-8. DOI PubMed

58. Artz JS, Dinner MI, Sampliner J. Breast reconstruction with a subcutaneous tissue expander followed with a polyurethane-covered silicone breast implant. Ann Plast Surg 1988;20:517-21. DOI PubMed

59. Hess DR. Retrospective studies and chart reviews. Respir Care 2004;49:1171-4. PubMed 